\title{
Effects of Non-Coherent and Coherent Light on Complete Blood Picture and Osmotic Fragility of Human Blood
}

Yousry M Mostafa ${ }^{1}$, Sherif N Amin ${ }^{2}$, Samir Abdalwahab ${ }^{1 *}$ and Alsayed AM Elsherbini ${ }^{1}$

${ }^{1}$ National Institute of Laser Enhanced Science, Cairo University, Egypt

${ }^{2}$ Kasr El-Aini Medical School, Cairo University, Egypt

\begin{abstract}
The erythrocytes through its life span undergo many oxidative stresses from various oxidants, free radicals, diabetes, lack of some antioxidant enzymes and some diseases. These oxidative stresses lose the normal rheological properties of blood cells, deformability and shorten life span of erythrocytes.
\end{abstract}

Aim: The present study is to evaluate the effects of non-coherent light (solar light) and He-Ne laser on Complete Blood Count (CBC) and osmotic fragility of erythrocytes.

Results: It is found that the non-coherent and coherent light decreased osmotic fragility of erythrocytes and some parameters of $\mathrm{CBC}$ are very influenced strongly by light irradiation.

Conclusion: The irradiation of blood by non-coherent and He-Ne laser improve its rheological properties and decreases the osmotic fragility of erythrocytes (increases the resistance of erythrocytes to hypotonic solution).

Keywords: He-Ne laser; Solar light, Complete blood count (CBC); Osmotic fragility

\section{Introduction}

There are widespread applications of low intensity laser irradiation in various areas of the medical field [1,2]. In 1989, 10.1\% of all blood components transfused in the USA were irradiated to prevent the graftversus-host disease and the percentage has certainly increased in more recent years [3]. Some experts even advocate universal irradiation of cellular blood components [4]. This experimental medicine practice requires detailed information on the mechanisms of their biological effects and the increasing understanding of the wavelength selective interaction and associated effects of laser irradiation acting on biologic tissue $[5,6]$. Despite the fact that the response of blood to the action of a low intensity laser radiation gives important information on the mechanism of interaction of laser irradiation with a living organism $[7,8]$. A wide research exists on the use of low intensity laser irradiation in different experimental biological models. The most used laser of low level laser thereby studies are He-Ne laser emitting light at a wavelength of $632.8 \mathrm{~nm}[5,9,10-13]$. Although some studies have been reported on the effect of low power laser irradiation on human blood parameters, especially for the parameter of RBC [7,14-16]. More research is needed to be done to understand the respond of this parameter with low level laser irradiation. The goal of the present work was to study the effect of non-coherent light (solar light) and He-Ne laser irradiation on osmotic fragility of red blood cells and complete blood count (CBC).

\section{Materials and Methods}

The human blood samples are obtained from donors, who were referred for various blood analyses, to assess the effect of non-coherent and coherent light on complete blood picture (CBC) and osmotic fragility.

\section{Materials}

1. EDTA anticoagulant from Sigma Company.

2. All the chemicals used for the preparation of reagents for the measurement of haemolysis were of annular grade and purchased from Merck Chemicals Ltd.

\section{Instrumentation}

1. Oriel Solar Simulator (Manufactured by Oriel, Corporation, USA), Oriel Solar Simulator which closely matches the light of the solar spectrum.

2. Laser light obtained from He-Ne laser at maximum power density $10 \mathrm{~mW}$ (632 nm, beam spot diameter $2 \mathrm{~mm}$ ) was used as radiation source.

3. CCD camera microscope present in National Institute of Laser Enhanced Science Cairo University.

4. Sysmex hematology analyzer (Sysmex KX-21, TOA Medical Electronic, Co, Kobe, Japan) for measurements of complete blood count. This apparatus found in central laboratories of ministry of health.

\section{Preparation of the samples}

Measurements of different parameters were performed immediately after irradiation (from 30 min-1 hour). Blood samples obtained from each of 40 donors, (20 donors for irradiation by non-coherent and 20 donors for irradiation by He-Ne laser) who were referred for various blood analysis, $6 \mathrm{ml}$ of blood were immediately treated with EDTA anticoagulant. Then the entire blood volume from first 20 individual donors were separated into 2 equal volumes and inserted into tubes of $1 \mathrm{~cm}$ diameter (one control and the anther for $\mathrm{He}-\mathrm{Ne}$ laser irradiation). To assure its homogeneity, the blood was stirred gently before and during irradiation in all samples at $3 \mathrm{~min}$ intervals approximately.

*Corresponding author: Samir Abdalwahab, National Institute of Laser Enhanced Science, Cairo University, Egypt, E-mail: samirabdalwahab@gmail.com

Received October 21, 2012; Accepted November 14, 2012; Published November 16, 2012

Citation: Mostafa YM, Amin SN, Abdalwahab S, Elsherbini AAM (2013) Effects of Non-Coherent and Coherent Light on Complete Blood Picture and Osmotic Fragility of Human Blood. J Blood Disorders Transf 4:134. doi:10.4172/21559864.1000135

Copyright: (c) 2013 Mostafa YM. This is an open-access article distributed under the terms of the Creative Commons Attribution License, which permits unrestricted use, distribution, and reproduction in any medium, provided the original author and source are credited. 
The other 20 donors for irradiation with non-coherent light, the blood put in Petri dish of $5 \mathrm{~cm}$ diameter and exposed to the light of solar simulator apparatus.

While in case of irradiation with He-Ne laser the setup is putting the blood in the tube of $1 \mathrm{~cm}$ diameter and length $6 \mathrm{~cm}$. All the samples were used for measurements of osmotic fragility and $\mathrm{CBC}$. The blood samples were all irradiated at room temperature $\left(23 \pm 2^{\circ} \mathrm{C}\right)$

\section{Irradiation procedure}

Light irradiation of non-coherent light: The non-coherent light obtained from very high intensity sources closely match solar spectra (Oriel Solar Simulator). For an assessment of non-coherent light effects, the samples of human blood are divided into two aliquots one control and the second for irradiation with non-coherent light In case of noncoherent light human blood irradiated in Petri dishes has diameters 5 $\mathrm{cm}$. in horizontal position at height of about one foot long solar light source. In this study we used spectrum with ultra violet. (Manufactured by Oriel, Corporation, USA). Output power $400 \mathrm{~mW}$, and exposure time $10 \mathrm{~min}$, fluence is $12.2 \mathrm{~J} / \mathrm{cm}^{2}$

Light irradiation of He-Ne laser: For an assessment of coherent light effects the samples of human blood are divided into two aliquots one control and the second for irradiation with He-Ne laser. The coherent light obtained from He-Ne laser at maximum output power 10 $\mathrm{mW}$ (632 nm, beam spot diameter $2 \mathrm{~mm}$ ) was used as radiation source.

The laser was continuous wave type, irradiating the blood samples directly (with no fiber optic), from up to down (only one point in the center of the test tube) and at perpendicular incidence on blood surface. The ratio between the beam spot and the test tube diameter was $\approx 2 \mathrm{~mm} / 10 \mathrm{~mm}$. so that $4 \%$ of the blood surface only was irradiated directly. It is obvious that a small part of the superficial cells or molecules only received the power density of laser mentioned above and the laser energy then spread into the entire blood volume. This irradiation dose was considered to be the laser energy per volume unit $\left(\mathrm{J} / \mathrm{cm}^{3}\right)$ rather than the laser energy per area surface unit $\left(\mathrm{J} / \mathrm{cm}^{2}\right)$.The laser output power is $10 \mathrm{~mW}$, irradiation time is $30 \mathrm{~min}$ and the fluence is $9 \mathrm{~J} / \mathrm{cm}^{3}$

For non-coherent light (solar light) the equation will be:-

$$
\text { Power }(\text { watt }) \times \text { time (Seconds) }
$$

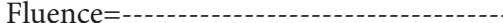

\section{Area}

$0.400 \times 10 \times 60$

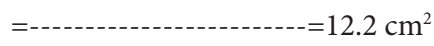

$3.14 \times(2.5)^{2}$

For He-Ne Laser the equation will be:-

Power $($ watt $) \times$ time $($ second $)$

Fluence $=$

Volume
$0.010 \times 30 \times 60$

$$
-=9 / \mathrm{cm}^{3}
$$

$$
2 \mathrm{ml}
$$

\section{In this study we measure the following parameters:}

CBC measurements: CBC measurements include 13 parameters, these are white blood cells, or leucocytes number (WBCs), red blood cells or erythrocytes count (RBCs), quantity of hemoglobin (HGB), hematocrit (HCT), mean corpuscular volume (MCV), mean corpuscular hemoglobin $(\mathrm{MCH})$, mean corpuscular hemoglobin concentration (MCHC), Platelet or thrombocytes count (PLT), Red cell distribution width (RDW) and Mean platelet volume (MPV).

Blood counts were performed on EDTA anticoagulated blood using an automated counting device (Sysmex KX-21, TOA Medical Electronic, Co. Kobe, Japan)

Measurement of erythrocytes osmotic fragility: Osmotic fragility of erythrocytes is a measure of resistance of erythrocytes to haemolysis by osmotic stress. The test consists of exposing red cells to decreasing strength of hypotonic saline solutions and measuring the degree of haemolysis colorimetrically at room temperature. The percentage of haemolysis is plotted on the vertical axis against decreasing saline concentration on the horizontal axis. Asymmetrical curve, sigmoidal in shape, is obtained in most subjects. It is essentially useful to record the concentration of sodium chloride solution causing $50 \%$ lysis (i.e. the median corpuscular fragility).

The extent of haemolysis in various concentrations of sodium chloride, buffered with phosphate at $\mathrm{pH} 7.4$ was determined by the method described by Dacie and Lewis [17]

The following solution/reagents were used for the measurement of hemolysis:

Stock solution of buffered sodium chloride, osmotically equivalent to $10 \% \mathrm{NaCl}$ :

$$
\begin{array}{lc}
\mathrm{NaCl}, & 90 \mathrm{gm} \\
\mathrm{Na}_{2} \mathrm{HPO}_{4} & 13.65 \mathrm{gm} \\
\mathrm{NaH}_{2} \mathrm{PO}_{4} & 2.43 \mathrm{gm}
\end{array}
$$

All these salts were dissolved in distilled water and the final volume was adjusted to one liter. This solution was kept in well stoppered bottle at room temperature. Practically osmotic fragility of erythrocytes was determined as follow: - The blood, $0.1 \mathrm{ml}$ is mixed with $2.5 \mathrm{ml}$ of citrate saline ( 1 part of $3.8 \%$ sodium citrate to 9 parts of $0.9 \% \mathrm{NaCl}, \mathrm{pH} 7.0$ ). 12 tubes are prepared containing $5 \mathrm{ml}$ of the following concentration $0.3 \%$, $0.32 \%, 0.34 \%, 0.36 \%, 0.38 \%, 0.4 \%, 0.42 \%, 0.44 \%, 0.46 \%, 0.48 \%, 0.5 \%$, and $0 \%$. To each of this dilution, is added $0.2 \mathrm{ml}$ of the blood-citratesaline mixture. The tubes are allowed to stand at room temperature for 10 minutes, and are then agitated and centrifuged at $2000 \mathrm{rpm}$ for 10 minutes (Figure 1). The contents of each tube are then decanted into a $1 \mathrm{~cm}$ cuvette, and the hemoglobin in the supernatant measured in a spectrophotometer at $540 \mathrm{~nm}$. The degree of hemolysis was calculated on assumption that the absorbance of a sample hemolyzed with distilled water equaled $100 \%(0.0 \mathrm{NaCl})$.

Percentage of hemolysis at each concentration of hypotonic saline was calculated as follows: 
100

\% lysis=------ $\times$ O.D. at the given concentration (O.D. at complete lysis of $\mathrm{NaCl}$ )

where O.D. is optical density.

Statistics analysis: In this work, the most crucial concern is the difference between the control and laser irradiation thus a paired $t$-test was used to evaluate the difference between the irradiated samples and non-irradiated control. All statistical analysis was performed with statistical package graph Pad software (Graph Pad software, Inc. San Diego, California, USA). For those with significant difference, the percentage of relative variance (R.V.) was calculated to evaluate the extent of the relative change between irradiated and non-irradiated samples.

\section{Results}

The results of the effects of non-coherent light and coherent light on human blood in vitro for CBC parameters of 40 donors before and after irradiation are shown in the following tables. A positive results in which the relative variation (R.V.) exceeded its relevant interval (R.I.). R.V. of a given blood parameter is the difference between its value after irradiation and before irradiation, divided by the value before irradiation.

$\mathrm{R} . \mathrm{V}=\Delta \mathrm{X} / \mathrm{X}$ (where $\Delta \mathrm{X}$ is difference between before and after irradiation)

R.I. \% is the ratio between the difference of its maximal and minimal normal value (divided by 2 ) and the mean value of the same maximal and minimal normal value R.I. $=(\max -\min$ normal value $/ \max +\min$ normal value)/2

\section{The effect of non-coherent light on CBC}

WBC: leukocyte count; normal values ranging between 6 and 8 thousands $/ \mathrm{mm}^{3}$.

Our experimental data (Table 1) indicated that the relative variations of WBC ranged between $-5.6 \%$ and $15 \%$ ( $\mathrm{P}$ value $=0.177$ ). Non-coherent light effect was relevant in $5 \%$ of cases (R.I.=14.3\%). In 14 cases out of 20, the variations were positive, they were negative in 5 cases and no effect was noticed in one case.

RBC: Erythrocytes count; normal values ranging between 4.5 and 5.4 millions $/ \mathrm{mm}^{3}$.

Our experimental data (Table 1) indicated that the relative variations of the $\mathrm{RBC}$ ranged between $10.7 \%$ and $23.2 \%$ ( $\mathrm{P}$ value $=0.0001$ ). The

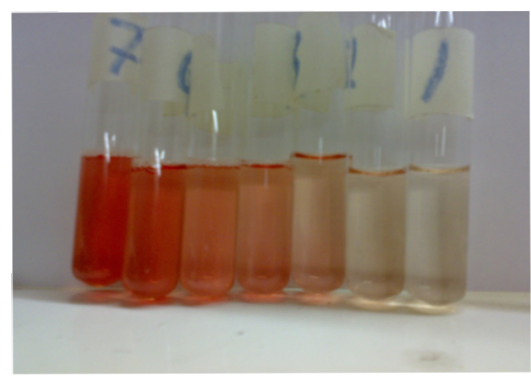

Figure 1: Osmotic fragility test of erythrocytes. non-coherent light effect was relevant in $70 \%$ of cases (R.I.=9\%). In 16 cases out of 20 , the variations were positive and in 4 cases were negative.

HBG: Hemoglobin concentration, normal values ranging between 14 and $16 \mathrm{gm} / \mathrm{dl}$.

Our experimental data (Table 1) indicated that the relative variations of $\mathrm{HBG}$ ranged between $-4.2 \%$ and $17.2 \%$ ( $\mathrm{P}$ value $=0.0001$ ). The non-coherent light effect was relevant in $50 \%$ of cases (R.I. $=6.6 \%$ ). In 18 cases out of 20 , the variations were positive, and in two cases they were negative.

HCT: Hematocrit, normal values ranging between 45 and $45 \%$.

Experimental data (Table 1) indicated that the relative variations of HCT ranged between $-4.5 \%$ and $8.9 \%$ ( $\mathrm{P}$ value $=0.0001$ ). Non-coherent light effect was relevant in $75 \%$ of cases (R.I. $=2.27 \%$ ). In 18 cases out of 20 , the variations were positive and in 2 cases they were negative.

MCV: Mean corpuscular volume, normal values ranging between 82 and $94 \mu \mathrm{m}^{3}$.

Experimental data (Table 1) indicated that the relative variation of MCV ranged between $-20 \%$ and $23.2 \%$ (P value $=0.0365$ ). The noncoherent light effect was relevant in $20 \%$ of cases (R.I. $=2.27 \%$ ). In 5 cases out of 20, the variation was positive, and 17 cases they were negative.

$\mathrm{MCH}$ : Mean corpuscular hemoglobin, normal values ranging between 25 and 33 picograms.

Experimental data (Table 1) indicated that the relative variations of the MCV ranged between $-20.9 \%$ and $20.5 \%$ ( $P$ value $=0.1139$ ). Noncoherent light effect was relevant in $5 \%$ of cases (R.I. $=13.8 \%$ ). In 8 cases out of 20, the variations were positive, and 12 cases they were negative.

MCHC: Mean corpuscular hemoglobin concentration, normal value ranging between 32 and $36 \%$.

Experimental data (Table 1) indicated the relative variations of MCHC ranged between $-6.3 \%$ and $9.8 \%$ (P value $=0.1145$ ) Non-coherent light effect was relevant in $20 \%$ of cases (R.I. $=5.88 \%$ ). In 14 cases out of 20 , the variations were positive, and 6 cases they were negative.

PLT: Platelet or thrombocytes count, normal values ranging between 250 and 400 thousands $/ \mathrm{mm}^{3}$.

Experimental data (Table 2) indicated that the relative variation of the PLT ranged between $-4.2 \%$ and $7.3 \%$ ( $\mathrm{P}$ value $=0.2254$ ). Noncoherent light was not relative in any case $0 \%$ (R.I. $=23 \%$ ). In 8 cases out of 20 , the variations were positive, and in 12 cases they were negative.

RDW: Red cell distribution width, normal values ranging between 14 and $16 \%$ are determined by automatic hemo-analyzer only. Experimental data (Table 2) indicated that the relative variations of the RDW ranged between $6 \%$ and $4.9 \%$ (P value $=0.1665$ ). The non-coherent light effect was not found to be relevant in any cases (R.I.=6.6\%). In 12 cases out of 20, the variations were positive, and in 6 cases they were negative and no effects in two cases.

MPV: Mean platelet volume, normal values ranging between 6 and $7 \mu \mathrm{m}^{3}$.

Experimental data (Table 2) indicated that the relative variations of the MPV ranged between $-10.8 \%-12.5 \%$ ( $\mathrm{P}$ value $=0.3847$ ). The noncoherent light effect was relevant in $10 \%$ of cases (R.I.=7.7\%). In 14 cases out of 20 , the variations were positive, and in 5 cases they were negative, and in one case no effect. 
The effect of non-coherent light (solar light) on human blood after $10 \mathrm{~min}$ irradiation (irradiance $12.2 \mathrm{~J} / \mathrm{cm}^{2}$ )

\begin{tabular}{|c|c|c|c|c|c|c|c|c|c|c|c|c|c|c|c|c|c|c|c|c|c|}
\hline & \multicolumn{3}{|c|}{ WBC } & \multicolumn{3}{|c|}{ RBC } & \multicolumn{3}{|c|}{ HBG } & \multicolumn{3}{|c|}{ HCT } & \multicolumn{3}{|c|}{ MCV } & \multicolumn{3}{|c|}{$\mathrm{MCH}$} & \multicolumn{3}{|c|}{$\mathrm{MCHC}$} \\
\hline & Ctrl & IRR & R.V. & Ctrl & IRR & R.V. & Ctrl & IRR & R.V. & Ctrl & IRR & R.V. & Ctrl & IRR & R.V. & Ctrl & IRR & R.V. & Ctrl & IRR & R.V. \\
\hline 1 & 9.0 & 9.2 & 2.2 & 4.63 & 5.1 & 10.2 & 10.0 & 11.1 & 11 & 32.0 & 9.2 & 8.1 & 69.1 & 67.84 & -1.8 & 21.6 & 21.76 & 0.7 & 31.3 & 32.08 & 2.5 \\
\hline 2 & 7.4 & 7.4 & 0 & 4.49 & 5.43 & 20.9 & 12.7 & 12.8 & 0.8 & 38.7 & 7.4 & 3.6 & 86.2 & 73.8 & -14.4 & 28.3 & 23.57 & -16.7 & 32.8 & 31.92 & -2.7 \\
\hline 3 & 4.9 & 5.5 & 12.2 & 4.37 & 4.9 & 12.1 & 11.7 & 12.9 & 10.3 & 35.0 & 5.5 & 5.7 & 80.1 & 75.5 & -5.7 & 26.8 & 26.33 & -1.8 & 33.4 & 34.86 & 4.4 \\
\hline 4 & 9.6 & 9.3 & -3.1 & 4.44 & 4.85 & 9.2 & 12.1 & 13.0 & 7.4 & 35.0 & 9.3 & 3.4 & 78.8 & 74.6 & -5.3 & 27.3 & 26.8 & -1.8 & 34.6 & 35.91 & 3.8 \\
\hline 5 & 6.8 & 7 & 2.9 & 4.79 & 5.61 & 17.1 & 13.4 & 14.2 & 6 & 37.5 & 34.6 & 4.3 & 78.3 & 69.7 & -11 & 28 & 25.31 & -9.6 & 35.7 & 36.31 & 1.7 \\
\hline 6 & 9 & 8.5 & -5.6 & 4.97 & 5.42 & 9.1 & 11.3 & 11.9 & 5.3 & 33.7 & 40.1 & 4.2 & 67.8 & 64.8 & -4.4 & 22.7 & 21.95 & -3.3 & 33.5 & 33.90 & 1.2 \\
\hline 7 & 7.7 & 7.5 & -2.6 & 4.54 & 5.44 & 19.8 & 11.6 & 12.0 & 3.4 & 35.3 & 37.0 & 5.1 & 77.8 & 68.2 & -12.3 & 25.6 & 22.05 & -13.9 & 32.9 & 32.34 & -1.7 \\
\hline 8 & 6.7 & 6.9 & 3 & 5.41 & 6.55 & 21.1 & 16.5 & 15.8 & -4.2 & 48.9 & 36.2 & 1.2 & 90.4 & 75.6 & -16.4 & 30.5 & 24.12 & -20.9 & 33.7 & 31.91 & -5.3 \\
\hline 9 & 9.6 & 10.3 & 7.3 & 4.79 & 4.53 & -5.4 & 13.8 & 14.2 & 2.9 & 42.2 & 39.1 & 2.1 & 88.1 & 95.1 & 7.9 & 28.8 & 31.34 & 8.8 & 32.7 & 32.94 & 0.7 \\
\hline 10 & 5.4 & 5.5 & 1.9 & 4.43 & 5.15 & 16.3 & 13.9 & 14.2 & 2.2 & 44 & 35.1 & -4.5 & 99.3 & 81.55 & -17.9 & 31.4 & 27.57 & -12.2 & 31.6 & 33.8 & 6.5 \\
\hline 11 & 9.7 & 10.1 & 4.1 & 4.84 & 5.20 & 7.4 & 10.6 & 11.9 & 12.3 & 33.5 & 37.1 & 4.5 & 69.2 & 67.30 & -2.7 & 21.9 & 22.88 & 4.5 & 31.6 & 34 & 7.6 \\
\hline 12 & 3.8 & 4.1 & 7.9 & 5.05 & 6.22 & 23.2 & 13.0 & 13.6 & 4.6 & 41.4 & 49.5 & -1.4 & 82.0 & 65.59 & -20 & 25.7 & 21.86 & -14.9 & 31.4 & 33.3 & 6.1 \\
\hline 13 & 6.6 & 7.5 & 13.6 & 4.30 & 5.00 & 16.3 & 11.8 & 12. 7 & 7.6 & 36.6 & 43.1 & 5.7 & 85.1 & 77.4 & -9 & 27.4 & 25.4 & -7.3 & 32.2 & 32.8 & 1.9 \\
\hline 14 & 8.4 & 9.1 & 8.3 & 4.59 & 4.1 & -10.7 & 11.8 & 12.7 & 7.6 & 36.4 & 42 & 4.4 & 79.3 & 92.68 & 16.9 & 25.7 & 30.97 & 20.5 & 32.4 & 33.4 & 3.1 \\
\hline 15 & 7.4 & 7.2 & -2.7 & 3.79 & 3.58 & -5.5 & 11.2 & 10.8 & -3.6 & 33.0 & 35.0 & 1.8 & 87.1 & 93.85 & 7.7 & 29.6 & 30.16 & 1.9 & 33.9 & 32.1 & -5.3 \\
\hline 16 & 11.8 & 12.0 & 1.7 & 4.44 & 5.15 & 16 & 10.9 & 12.0 & 10.1 & 32.5 & 40.8 & 8.3 & 73.2 & 68.3 & -6.7 & 24.5 & 23.3 & -4.9 & 33.5 & 34.1 & 1.8 \\
\hline 17 & 6.0 & 6.9 & 15 & 4.61 & 5.19 & 12.6 & 12.2 & 14.3 & 17.2 & 36.1 & 38.7 & 6.6 & 78.3 & 74.2 & -5.2 & 26.5 & 27.6 & 4.2 & 33.8 & 37.1 & 9.8 \\
\hline 18 & 7.4 & 7.8 & 5.4 & 4.79 & 5.50 & 14.8 & 11.6 & 12.5 & 7.8 & 34.8 & 38.0 & 3.7 & 72.7 & 65.6 & -9.8 & 24.2 & 22.7 & -6.2 & 33.3 & 34.6 & 3.9 \\
\hline 19 & 6.9 & 7.1 & 2.9 & 4.18 & 4.5 & 7.7 & 10.3 & 11.1 & 7.8 & 30.4 & 33.6 & 8.9 & 72.7 & 73.55 & 1.2 & 24.6 & 24.67 & 0.3 & 33.9 & 33.53 & -1.1 \\
\hline 20 & 11.3 & 11.1 & -1.8 & 4.40 & 4.35 & -1.1 & 9.7 & 9.9 & 2.1 & 30.1 & 35.2 & 9 & 68.4 & 75.4 & 23.2 & 22.0 & 22.76 & 3.5 & 32.2 & 30.18 & -6.3 \\
\hline $\begin{array}{c}\text { Mean } \\
\pm \\
\text { SD }\end{array}$ & $\begin{array}{c}7.770 \pm \\
2.051\end{array}$ & $\begin{array}{c}8.000 \\
\pm \\
1.965\end{array}$ & & $\begin{array}{c}4.593 \pm \\
0.3458\end{array}$ & $\begin{array}{c}5.089 \\
\pm \\
0.6804\end{array}$ & & $\begin{array}{c}12.011 \\
\pm 1.582\end{array}$ & $\begin{array}{c}12.68 \\
\pm \\
1.428\end{array}$ & & $\begin{array}{c}36.36 \\
\pm \\
4.726\end{array}$ & $\begin{array}{c}37.78 \\
\pm \\
3.996\end{array}$ & & $\begin{array}{c}79.20 \\
\pm \\
8.387\end{array}$ & $\begin{array}{c}75.03 \\
\pm \\
9.280\end{array}$ & & $\begin{array}{c}26.16 \\
\pm \\
2.851\end{array}$ & $\begin{array}{c}25.16 \\
\pm \\
3.074\end{array}$ & & $\begin{array}{c}33.02 \\
\pm \\
1.135\end{array}$ & $\begin{array}{c}33.55 \\
\pm \\
1.666\end{array}$ & \\
\hline $\begin{array}{l}P \\
\text { alue }\end{array}$ & & 0.177 & & & 0.0001 & & & 0.0001 & & & 0.00 & & & 0.03 & & & 0.11 & & & 0.1145 & \\
\hline
\end{tabular}

Table 1: The effect of non-coherent light (solar light) on human blood after $10 \mathrm{~min}$ irradiation (irradiance $12.2 \mathrm{~J} / \mathrm{cm}^{2}$ ).

The effect of non-coherent light (solar light) on human blood after $10 \mathrm{~min}$ irradiation (irradiance $12.2 \mathrm{~J} / \mathrm{cm}^{2}$ )

\begin{tabular}{|c|c|c|c|c|c|c|c|c|c|c|c|c|c|c|c|c|c|c|}
\hline & \multicolumn{3}{|c|}{ PLT } & \multicolumn{3}{|c|}{ RDW } & \multicolumn{3}{|c|}{ MPV } & \multicolumn{3}{|c|}{ Lymph } & \multicolumn{3}{|c|}{ MONO } & \multicolumn{3}{|c|}{ GRAN } \\
\hline & Ctrl & IRR & R.V. & Ctrl & IRR & R.V. & Ctrl & IRR & R.V. & Ctrl & IRR & R.V. & Ctrl & IRR & R.V. & Ctrl & IRR & R.V. \\
\hline 1 & 396 & 381 & -3.8 & 12.1 & 11.8 & -2.5 & 10.1 & 10.5 & 4 & 48.9 & 45.7 & -6.4 & 8.9 & 7.60 & -14.6 & 42.2 & 44.6 & 5.7 \\
\hline 2 & 280 & 271 & -3.2 & 13.1 & 13.4 & 2.3 & 20.4 & 18.2 & -10.8 & 40.5 & 39.2 & -3.8 & 10.8 & 10.8 & 0 & 48.6 & 50 & 2.9 \\
\hline 3 & 274 & 265 & -3.3 & 11.7 & 11.5 & -1.7 & 11.1 & 11.0 & -0.9 & 59.2 & 50.9 & -14 & 12.2 & 12.7 & 4.1 & 28.6 & 25.5 & -10.8 \\
\hline 4 & 361 & 371 & 2.8 & 10.0 & 10.5 & 5 & 8.7 & 9.1 & 4.6 & 31.3 & 29.0 & -7.3 & 10.4 & 9.7 & -6.7 & 58.3 & 64.5 & 10.6 \\
\hline 5 & 272 & 266 & -2.2 & 10 & 10.1 & 1 & 8.7 & 9.1 & 4.6 & 32.4 & 34.3 & 5.9 & 13.2 & 11.4 & -13.6 & 54.4 & 51.4 & -5.5 \\
\hline 6 & 301 & 295 & -2 & 9.3 & 9.6 & 3.2 & 10.2 & 11.0 & 7.8 & 64.4 & 63.5 & -1.4 & 7.8 & 8.2 & 5.1 & 27.8 & 34.1 & 22.7 \\
\hline 7 & 419 & 402 & -4.1 & 11.6 & 11.0 & -5.2 & 9.5 & 9.8 & 3.2 & 32.5 & 32.4 & -0.3 & 6.5 & 5.8 & -10.8 & 67.5 & 70.7 & 4.7 \\
\hline 8 & 227 & 239 & 5.3 & 14.9 & 15.3 & 2.7 & 11.4 & 12.1 & 6.1 & 32.8 & 33.3 & 1.5 & 4.5 & 4.3 & -4.4 & 62.7 & 59.4 & -5.3 \\
\hline 9 & 285 & 273 & -4.2 & 13.3 & 13.5 & 1.5 & 12.4 & 12.6 & 1.6 & 30.2 & 29.1 & -3.6 & 9.4 & 6.8 & -27.7 & 60.4 & 57.3 & -5.1 \\
\hline 10 & 214 & 215 & 0.5 & 13.4 & 12.6 & -6 & 14.3 & 14.3 & 0 & 29.6 & 29.1 & -1.7 & 9.3 & 10.9 & 17.2 & 61.4 & 60 & -1.8 \\
\hline 11 & 310 & 315 & 1.6 & 11.5 & 11.8 & 2.6 & 9.6 & 10.1 & 5.2 & 60.8 & 56.4 & -6.2 & 10.3 & 10.9 & 5.8 & 28.9 & 28.7 & -0.7 \\
\hline 12 & 186 & 180 & -3.2 & 11.4 & 11.4 & 0 & 16.4 & 16.3 & -0.6 & 50 & 48.8 & -2.4 & 13.2 & 12.2 & -7.6 & 36.8 & 31.7 & -13.9 \\
\hline 13 & 151 & 162 & 7.3 & 12.5 & 12.3 & -1.6 & 16.8 & 15.7 & -6.5 & 22.7 & 25.3 & 11.5 & 10.6 & 8 & -24.5 & 66.7 & 54.7 & -18 \\
\hline 14 & 263 & 261 & -0.8 & 11.7 & 12.1 & 3.4 & 11.6 & 11.9 & 2.6 & 48.80 & 47.3 & -3.1 & 16.7 & 16.5 & -1.2 & 34.5 & 28.6 & -17.1 \\
\hline 15 & 149 & 153 & 2.7 & 12.6 & 13 & 3.2 & 13.3 & 13.1 & -1.5 & 44.6 & 43.1 & -3.4 & 8.1 & 9.7 & 19.8 & 47.3 & 50 & 5.7 \\
\hline 16 & 624 & 615 & -1.4 & 14 & 14.2 & 1.4 & 9.7 & 9.9 & 2.1 & 59.3 & 59.2 & -0.2 & 14.4 & 14.2 & -1.4 & 26.3 & 25 & -4.9 \\
\hline 17 & 239 & 247 & 3.3 & 10. 7 & 10.7 & 0 & 10.7 & 11.1 & 3.7 & 51.7 & 43.5 & -16.2 & 11.7 & 8.7 & -25.6 & 36.7 & 34.8 & -5.2 \\
\hline 18 & 430 & 429 & -0.2 & 10. 2 & 10.7 & 4.9 & 8.6 & 9.1 & 5.8 & 62.2 & 60.3 & -3.1 & 13.5 & 14.1 & 4.4 & 24.3 & 20.5 & -15.6 \\
\hline 19 & 500 & 488 & -2.4 & 9.5 & 9.3 & -2.1 & 9.7 & 10.1 & 4.1 & 60.9 & 56.3 & -7.6 & 17.4 & 18.3 & 5.2 & 21.7 & 22.5 & 3.7 \\
\hline 20 & 388 & 391 & 0.8 & 12.2 & 12.6 & 3.3 & 8.0 & 9.0 & 12.5 & 61.1 & 59.5 & -2.6 & 13.3 & 14.4 & 8.3 & 25.7 & 27.9 & 8.6 \\
\hline $\begin{array}{c}\text { Mean } \\
\pm \\
\mathrm{SD}\end{array}$ & $\begin{array}{c}313.5 \\
\pm \\
119.5\end{array}$ & $\begin{array}{c}311.0 \\
\pm \\
115.5\end{array}$ & & $\begin{array}{c}11.74 \\
\pm \\
1.546\end{array}$ & $\begin{array}{c}11.87 \\
\pm \\
1.574\end{array}$ & & $\begin{array}{c}11.56 \\
\pm \\
3.228\end{array}$ & $\begin{array}{c}11.70 \\
\pm \\
2.630\end{array}$ & & $\begin{array}{c}46.20 \\
\pm \\
13.64\end{array}$ & $\begin{array}{c}44.31 \\
\pm \\
12.33\end{array}$ & & $\begin{array}{c}11.11 \\
\pm \\
3.244\end{array}$ & $\begin{array}{c}10.76 \\
\pm \\
3.591\end{array}$ & & $\begin{array}{c}43.04 \\
\pm \\
15.85\end{array}$ & $\begin{array}{c}42.10 \\
\pm \\
15.82\end{array}$ & \\
\hline$P$ value & & 0.2254 & & & 0.1665 & & & 0.3847 & & & 0.0070 & & & 0.2655 & & & 0.3416 & \\
\hline
\end{tabular}

Table 2: The effect of non-coherent light (solar light) on human blood after $10 \mathrm{~min}$ irradiation (irradiance $12.2 \mathrm{~J} / \mathrm{cm}^{2}$ ). 
Lymph: Lymphocyte number, in concentration, normal values ranging between 20 and $35 \%$.

Experimental data (Table 2) indicated that the relative variations of the lymphocyte number ranged between $-16.2 \%$ and $11.5 \%(\mathrm{P}$ value $=0.0070$ ). The non-coherent light effect was not found to be relevant in any instance (R.I. $=25 \%$ ). In 3 cases out of 20 , the variations were positive, and in 17 cases they were negative.

Mono: Monocytes number, in concentration, normal values ranging between 5 and $10 \%$.

Experimental data (Table 2) indicated that the relative variations of the monocytes ranged between $-27.7 \%$ and $19.8 \%$ ( $P$ value $=0.2655$ ). The non-coherent light effect was not relevant in any case (R.I.=33\%). In 8 cases out of 20 , the variations were positive, and in 11 cases they were negative and no effect in one case.

GRAN: Granulocytes number, in concentration, normal values ranging between $60-68 \%$.

Experimental data (Table 2) indicated that the relative variation of the Gran ranged between $-18 \%$ and $22.7 \%$ (P value $=0.3416$ ). The noncoherent light effect was relevant in $15 \%$ of cases (R.I. $=6.25 \%)$. In 8 cases out of 20 the variations were positive and in 12 cases they were negative.

\section{The effect of He-Ne laser on CBC}

WBC: Leukocyte count; normal values ranging between 6 and 8 thousands $/ \mathrm{mm}^{3}$.

Experimental data (Table 3) indicated that the relative variations of WBC ranged between $-9.1 \%$ and $14.8 \%$ ( $\mathrm{P}$ value $=0.5603$ ). He-Ne laser irradiation effect was relevant in $10 \%$ of cases (R.I. $=14.3 \%)$. In 10 cases out of 20 , the variations were positive; they were negative in 10 cases.

RBC: Erythrocytes count; normal values ranging between 4.5 and 5.4 millions $/ \mathrm{mm}^{3}$.

Experimental data (Table 3 ) indicated that the relative variations of the RBC ranged between $-6.1 \%$ and $21.7 \%$ ( $\mathrm{P}$ value $=0.0001$ ). $\mathrm{He}-\mathrm{Ne}$ laser irradiation effect was relevant in $30 \%$ of cases (R.I.=9\%). In 19 cases out of 20, the variations were positive and in 1 case were negative.

HBG: Hemoglobin concentration, normal values ranging between 14 and $16 \mathrm{gm} / \mathrm{dl}$.

Experimental data (Table 3 ) indicated that the relative variations of HBG ranged between $-0.8 \%$ and $16.8 \%$ (P value $=0.0001$ ). He-Ne laser irradiation effect was relevant in $40 \%$ of cases (R.I. $=6.6 \%$ ). In 19 cases out of 20, the variations were positive, and in one case it was negative.

HCT: Hematocrit, normal values ranging between 45 and $45 \%$.

Experimental data (Table 3) indicated that the relative variations of HCT ranged between $0.3 \%$ and $8.2 \%$ (P value $=0.0001$ ). He-Ne laser irradiation effect was relevant in $75 \%$ of cases (R.I. $=2.27 \%)$. In all cases of 20 , the variations were positive.

MCV: Mean corpuscular volume, normal values ranging between 82 and $94 \mu \mathrm{m}^{3}$.

Experimental data (Table 3) indicated that the relative variation of MCV ranged between $-15.7 \%$ and $11 \%$ ( $\mathrm{P}$ value $=0.1107$ ). He-Ne laser irradiation effect was relevant in $15 \%$ of cases (R.I. $=2.27 \%$ ). In 6 cases out of 20, the variation were positive, and 14 cases they were negative

$\mathrm{MCH}$ : Mean corpuscular hemoglobin, normal values ranging between 25 and 33 picograms.

Experimental data (Table 3) indicated that the relative variations of the $\mathrm{MCH}$ ranged between $-13.3 \%$ and $11.8 \%$ ( $\mathrm{P}$ value $=0.3657$ ). HeNe laser irradiation effect was relevant in $0 \%$ of cases (R.I.=13.8\%). In 9 cases out of 20 , the variations were positive, and 10 cases they were negative. And in one case no effect.

MCHC: Mean corpuscular hemoglobin concentration, normal value ranging between 32 and $36 \%$ ). Experimental data (Table 3) indicated the relative variations of $\mathrm{MCHC}$ ranged between $-8.3 \%$ and $13.3 \%$ (P value $=0.0688$ ). He-Ne laser irradiation effect was relevant in $5 \%$ of cases (R.I. $=5.88 \%$ ). In 14 cases out of 20 , the variations were positive, and 6 cases they were negative.

PLT: Platelet or thrombocytes count, normal values ranging between 250 and 400 thousands $/ \mathrm{mm}^{3}$.

Experimental data (Table 4) indicated that the relative variation of the PLT ranged between $-6.5 \%$ and $23 \%$ ( $\mathrm{P}$ value $=0.8492$ ). He-Ne laser irradiation effect was relevant in $5 \%$ of cases (R.I. $=23 \%$ ). In 11 cases out of 20 , the variations were positive, and in 9 cases they were negative.

RDW: Red cell distribution width, normal values ranging between 14 and $16 \%$ are determined by automatic hemoanalyzer only. Experimental data (Table 4) indicated that the relative variations of the RDW ranged between $-8.5 \%$ and $5.3 \%$ (P value $=0.2005$ ). $\mathrm{He}-\mathrm{Ne}$ laser irradiation effect was not relevant in any cases (R.I. $=6.6 \%$ ). In 8 cases out of 20, the variations were positive, and in 10 cases they were negative and no effects in two cases. $7 \mu \mathrm{m}^{3}$.

MPV: Mean platelet volume, normal values ranging between 6 and

Experimental data (Table 4) indicated that the relative variations of the MPV ranged between $1 \%$ and $8.5 \%$ ( $\mathrm{P}$ value $=0.0001$ ). He-Ne laser irradiation effect was relevant in $15 \%$ of cases (R.I. $=7.7 \%)$. In all cases of 20 , the variations were positive.

Lymph: Lymphocyte number, in concentration, normal values ranging between 20 and $35 \%$.

Experimental data (Table 4) indicated that the relative variations of the lymphocyte number ranged between $-19.4 \%$ and $27 \%$ (P value $=0.5742$ ). The He-Ne laser light effect was relevant in $5 \%$ of cases (R.I. $=25 \%$ ). In 10 cases out of 20 , the variations were positive, and in 10 cases they were negative.

Mono: Monocytes number, in concentration, normal values ranging between 5 and 10\%) experimental data (Table 4) indicated that the relative variations of the Monocytes ranged between $-44.7 \%$ and $23.9 \%$ ( $\mathrm{P}$ value $=0.4269$ ). The He-Ne laser light effect was not relevant in any case (R.I. $=33 \%$ ). In 9 cases out of 20 , the variations were positive, and in 11 cases they were negative.

GRAN: Granulocyte number, in concentration, normal values ranging between $60-68 \%$.

Experimental data (Table 4) indicated that the relative variation of the Gran ranged between $-16.4 \%$ and $13.9 \%$ (P value $=0.5431)$. The He$\mathrm{Ne}$ laser light effect was relevant in $30 \%$ of cases (R.I. $=6.25 \%$ ). In 8 cases out of 20 the variations were positive and in 12 cases they were negative.

\section{The effects of non-coherent and coherent light on osmotic fragility of erythrocytes}

Osmotic fragility is a test that measures the resistance of erythrocytes 


\begin{tabular}{|c|c|c|c|c|c|c|c|c|c|c|c|c|c|c|c|c|c|c|c|c|c|}
\hline \multicolumn{22}{|c|}{ The effect of He-Ne Laser light on human blood after $30 \mathrm{~min}$ irradiation (irradiance $9 \mathrm{~J} / \mathrm{cm}^{2}$ ) } \\
\hline & \multicolumn{3}{|c|}{ WBC } & \multicolumn{3}{|c|}{ RBC } & \multicolumn{3}{|c|}{ HBG } & \multicolumn{3}{|c|}{ НСТ } & \multicolumn{3}{|c|}{ MCV } & \multicolumn{3}{|c|}{$\mathrm{MCH}$} & \multicolumn{3}{|c|}{ MCHC } \\
\hline & Ctrl & IRR & R.V. & Ctrl & IRR & R.V. & Ctrl & IRR & R.V. & Ctrl & IRR & R.V. & Ctrl & IRR & R.V. & Ctrl & IRR & R.V. & Ctrl & IRR & R.V. \\
\hline 1 & 8.0 & 8.5 & 6.3 & 5.55 & 5.8 & 4.5 & 14.0 & 14.9 & 6.4 & 42.9 & 43.4 & 1.2 & 77 & 74.82 & -2.8 & 25.2 & 25.7 & 2 & 32.7 & 34.33 & 5 \\
\hline 2 & 11.0 & 10.5 & -4.5 & 4.56 & 5.1 & 11.8 & 12.2 & 13.2 & 8.2 & 37.6 & 39 & 3.7 & 83 & 76.47 & -7.9 & 26.7 & 25.9 & -3 & 32.4 & 33.84 & 4.4 \\
\hline 3 & 2.7 & 3.1 & 14.8 & 4.23 & 4.85 & 14.7 & 12.5 & 12.9 & 3.2 & 37.6 & 38.9 & 3.5 & 89 & 80.20 & -9.9 & 29.4 & 26.6 & -9.5 & 33.2 & 33.16 & -0.1 \\
\hline 4 & 3.4 & 3.9 & 14.7 & 4.18 & 4.95 & 18.4 & 12.6 & 12.9 & 2.3 & 37.2 & 38.2 & 2.7 & 89 & 77.17 & -13.3 & 30.1 & 26.1 & -13.3 & 33.8 & 33.76 & -0.1 \\
\hline 5 & 5.4 & 5.1 & -5.6 & 4.78 & 4.97 & 0.2 & 13.6 & 14.1 & 3.7 & 40.5 & 42 & 3.7 & 85 & 84.50 & -0.5 & 28.5 & 28.4 & -0.4 & 33.7 & 33.57 & -0.4 \\
\hline 6 & 9.6 & 9.4 & -2.1 & 4.79 & 4.97 & 3.8 & 11.9 & 12.6 & 5.9 & 35.2 & 36.8 & 4.5 & 74 & 74.04 & 0.1 & 24.7 & 25.35 & 2.6 & 33.5 & 34.23 & 2.2 \\
\hline 7 & 6.3 & 6.1 & -3.2 & 4.96 & 5.2 & 4.8 & 13.9 & 14.5 & 4.3 & 42.0 & 43.1 & 2.6 & 85 & 82.88 & -2.5 & 28.1 & 27.88 & -0.8 & 33.1 & 33.64 & 1.6 \\
\hline 8 & 5.7 & 5.5 & -3.5 & 5.02 & 5.56 & 10.8 & 12.9 & 13.4 & 3.9 & 38.9 & 39.0 & 0.3 & 77 & 70.14 & -8.9 & 25.7 & 24.1 & -6.2 & 33.2 & 34.35 & 3.5 \\
\hline 9 & 6.4 & 6.5 & 1.6 & 5.50 & 5.65 & 2.7 & 12.1 & 12.5 & 3.3 & 38.4 & 39.2 & 2.1 & 70 & 69.38 & -0.9 & 21.9 & 22.12 & 1 & 31.4 & 31.88 & 1.4 \\
\hline 10 & 3.5 & 3.9 & 11.4 & 4.19 & 5.1 & 21.7 & 12.4 & 13.2 & 6.5 & 37.8 & 38.7 & 2.4 & 90 & 75.88 & -15.7 & 29.5 & 25.88 & -12.3 & 32.8 & 34.10 & 4 \\
\hline 11 & 6.3 & 6.7 & 6.3 & 5.86 & 6.2 & 5.8 & 16.1 & 16.5 & 2.5 & 48.2 & 49.1 & 1.9 & 82.0 & 79.19 & -3.4 & 27.5 & 26.61 & -3.2 & 33.4 & 33.60 & 0.6 \\
\hline 12 & 5.5 & 5.00 & -9.1 & 5.35 & 5.55 & 3.7 & 15.9 & 16.2 & 1.9 & 45.2 & 46.4 & 2.7 & 84 & 83.60 & -0.5 & 29.4 & 29.18 & -0.7 & 34.9 & 34.91 & 0.3 \\
\hline 13 & 5.9 & 6.2 & 5.1 & 4.51 & 4.7 & 4.2 & 13.3 & 14.1 & 6 & 39.9 & 41.8 & 2.3 & 86 & 88.9 & 3.4 & 29.4 & 30 & 2 & 34.2 & 33.73 & -1.4 \\
\hline 14 & 7.1 & 7.5 & 5.6 & 5.11 & 4.8 & -6.1 & 13.6 & 13.9 & 2.2 & 40.2 & 42.1 & 4.7 & 79 & 87.7 & 11 & 26.5 & 28.95 & 9.2 & 33.9 & 33.01 & -2.6 \\
\hline 15 & 11.2 & 11.1 & -0.9 & 4.42 & 4.64 & 5 & 12.8 & 12.7 & -0.8 & 38.9 & 42.1 & 8.2 & 88 & 90.7 & 3.1 & 29.0 & 27.37 & -5.6 & 32.9 & 30.16 & -8.3 \\
\hline 16 & 6.8 & 6.5 & -4.4 & 4.68 & 4.9 & 4.7 & 12.8 & 13.7 & 7 & 38.5 & 40.1 & 4.2 & 82 & 87.8 & 7.1 & 27.3 & 27.96 & 2.7 & 33.2 & 34.16 & 2.9 \\
\hline 17 & 5.4 & 5.7 & 5.6 & 5.40 & 5.90 & 9.3 & 11.6 & 12.7 & 9.5 & 35.7 & 37.1 & 3.9 & 66.1 & 62.88 & -4.9 & 21.5 & 21.5 & 0 & 32.5 & 34.23 & 5.3 \\
\hline 18 & 13.0 & 12.8 & -1.5 & 4.50 & 4.55 & 1.1 & 11.0 & 11.5 & 4.5 & 33.6 & 34.1 & 1.5 & 74.7 & 74.94 & 0.3 & 24.4 & 25.27 & 3.6 & 32.7 & 33.72 & 3.1 \\
\hline 19 & 7.9 & 7.8 & -1.3 & 4.30 & 4.5 & 4.7 & 9.5 & 11.1 & 16.8 & 29.7 & 30.6 & 3 & 69.1 & 68 & -1.6 & 22.1 & 24.7 & 11.8 & 32.0 & 36.27 & 13.3 \\
\hline 20 & 6.5 & 6.7 & 3.1 & 5.53 & 5.83 & 5.4 & 16.3 & 17.2 & 1.9 & 47.0 & 49.3 & 4.9 & 85.0 & 84.5 & -0.6 & 29.5 & 29.7 & 0.7 & 34.7 & 35.1 & 1.1 \\
\hline $\begin{array}{c}\text { Mean } \\
\pm \\
\text { SD }\end{array}$ & $\begin{array}{c}6.880 \pm \\
2.651\end{array}$ & $\begin{array}{c}6.925 \\
\pm \\
2.509\end{array}$ & & $\begin{array}{l}4.871 \pm \\
0.5213\end{array}$ & $\begin{array}{l}5.186 \pm \\
0.4992\end{array}$ & & $\begin{array}{c}13.05 \pm \\
1.673\end{array}$ & $\begin{array}{c}13.69 \\
\pm \\
1.571\end{array}$ & & $\begin{array}{c}39.25 \\
\pm \\
4.381\end{array}$ & $\begin{array}{c}40.55 \\
\pm \\
4.542\end{array}$ & & $\begin{array}{c}80.75 \\
\pm \\
7.086\end{array}$ & $\begin{array}{c}78.68 \\
\pm \\
7.658\end{array}$ & & $\begin{array}{c}26.82 \\
\pm \\
2.754\end{array}$ & $\begin{array}{c}26.46 \\
\pm \\
2.313\end{array}$ & & $\begin{array}{l}33.21 \pm \\
0.8565\end{array}$ & $\begin{array}{c}33.79 \\
\pm \\
1.220\end{array}$ & \\
\hline $\begin{array}{c}P \\
\text { value }\end{array}$ & & 603 & & & 0.0001 & & & 001 & & & 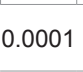 & & & 1107 & & & 0.3657 & & & 688 & \\
\hline
\end{tabular}

Table 3: The effect of He-Ne Laser light on human blood after 30 min irradiation (irradiance $9 \mathrm{~J} / \mathrm{cm}^{2}$ )

\begin{tabular}{|c|c|c|c|c|c|c|c|c|c|c|c|c|c|c|c|c|c|c|}
\hline \multicolumn{19}{|c|}{ The effect of He-Ne Laser light on human blood after $30 \mathrm{~min}$ irradiation (irradiance $9 \mathrm{~J} / \mathrm{cm}^{2}$ ) } \\
\hline & \multicolumn{3}{|c|}{ PLT } & \multicolumn{3}{|c|}{ RDW } & \multicolumn{3}{|c|}{ MPV } & \multicolumn{3}{|c|}{ LYMPH } & \multicolumn{3}{|c|}{ MONO } & \multicolumn{3}{|c|}{ GRAN } \\
\hline & Ctrl & IRR & R.V. & Ctrl & IRR & R.V. & Ctrl & IRR & R.V. & Ctrl & IRR & R.V. & Ctrl & IRR & R.V. & Ctrl & IRR & R.V. \\
\hline 1 & 360 & 375 & 4.2 & 15.6 & 15.0 & -3.8 & 10.1 & 10.2 & 1 & 17.5 & 19.5 & 11.4 & 7.5 & 6.9 & -8 & 75 & 68.7 & -8.4 \\
\hline 2 & 377 & 370 & -1.9 & 13.3 & 14.0 & 5.3 & 9.5 & 9.8 & 3.2 & 20.9 & 20.6 & -1.4 & 7.3 & 6.8 & -6.8 & 71.8 & 68.3 & -9.1 \\
\hline 3 & 243 & 257 & 5.8 & 12.6 & 12.4 & -1.6 & 9.7 & 10.2 & 5.2 & 29.6 & 30 & 1.4 & 11.1 & 7.4 & -33.3 & 59.3 & 49.6 & -16.4 \\
\hline 4 & 61 & 75 & 23 & 13.4 & 14.0 & 4.5 & 11.3 & 11.9 & 5.3 & 38.2 & 30.8 & -19.4 & 11.8 & 12.8 & 8.5 & 50 & 43.6 & -12.8 \\
\hline 5 & 116 & 110 & -5.2 & 16.5 & 15.1 & -8.5 & 10.0 & 10.6 & 6 & 18.5 & 23.5 & 27 & 9.3 & 7.8 & -16.1 & 72.2 & 74.5 & 3.2 \\
\hline 6 & 317 & 300 & -5.4 & 15.3 & 15.1 & -1.3 & 9.9 & 10.1 & 2 & 43.8 & 45.7 & 4.3 & 7.3 & 8.5 & 16.4 & 47.9 & 46.8 & -2.3 \\
\hline 7 & 321 & 300 & -6.5 & 15.2 & 15.0 & -1.3 & 9.3 & 9.4 & 1.1 & 28.6 & 26.2 & -8.4 & 11.1 & 9.8 & -11.7 & 60.3 & 67.2 & 11.1 \\
\hline 8 & 241 & 247 & 2.5 & 15.7 & 15.4 & -1.9 & 10.4 & 11.0 & 5.8 & 33.3 & 30.9 & -7.2 & 8.8 & 10.9 & 23.9 & 57.9 & 61.8 & 6.7 \\
\hline 9 & 302 & 307 & 1.7 & 16.0 & 14.7 & -8.1 & 9.9 & 10.7 & 8.1 & 12.5 & 13.8 & 10.4 & 6.3 & 7.7 & 22.2 & 81.2 & 76.9 & -5.3 \\
\hline 10 & 229 & 235 & 2.6 & 16.3 & 15.5 & -4.9 & 9.5 & 9.7 & 2.1 & 28.6 & 23.1 & -19.2 & 11.4 & 7.7 & -32.5 & 60 & 59 & -1.7 \\
\hline 11 & 252 & 247 & -2 & 14.4 & 14.9 & 3.5 & 9.4 & 10.2 & 8.5 & 15.9 & 16.4 & 3.1 & 9.5 & 7.5 & -21.1 & 74.6 & 70.1 & -9 \\
\hline 12 & 292 & 301 & 3.1 & 13.0 & 13.2 & 1.5 & 10.3 & 10.9 & 5.8 & 34.5 & 34 & -1.4 & 16.4 & 20 & 22 & 52.7 & 60 & 13.9 \\
\hline 13 & 316 & 326 & 3.2 & 15.0 & 14.8 & -1.3 & 9.3 & 10 & 7.5 & 35.6 & 37.1 & 2.4 & 6.8 & 4.8 & -29.4 & 55.9 & 51.6 & -7.7 \\
\hline 14 & 729 & 696 & -4.5 & 14.6 & 14.9 & 2.1 & 8.4 & 9.1 & 8.3 & 40.8 & 40 & -2 & 9.9 & 10.7 & 8.1 & 49.3 & 44 & -10.8 \\
\hline 15 & 438 & 446 & 1.8 & 15.4 & 15.4 & 0 & 9.1 & 9.2 & 1.1 & 19.6 & 21.6 & 10.2 & 8.9 & 9.9 & 11.2 & 71.4 & 69.4 & -2.8 \\
\hline 16 & 349 & 356 & 2 & 15.1 & 14.8 & -2 & 9.7 & 10.2 & 5.2 & 14.7 & 16.9 & 15 & 7.4 & 7.7 & 4.1 & 77.9 & 80 & 2.7 \\
\hline 17 & 414 & 410 & -1 & 11.8 & 11.8 & 0 & 10.2 & 10.5 & 2.9 & 53.7 & 49.3 & -11.1 & 8.2 & 9.9 & 10.8 & 35.2 & 38.8 & 10.2 \\
\hline 18 & 360 & 361 & 0.3 & 13.3 & 12.4 & -6.8 & 9.7 & 10.2 & 5.2 & 61.5 & 64.1 & 13.1 & 13.1 & 12.5 & -4.6 & 25.4 & 25 & -1.6 \\
\hline 19 & 377 & 365 & -3.2 & 12.8 & 13.0 & 1.6 & 8.4 & 8.8 & 4.8 & 59.5 & 57.9 & -2.7 & 7.6 & 6.5 & -14.5 & 32.9 & 36.9 & 12.2 \\
\hline 20 & 249 & 248 & -0.4 & 12.0 & 12.4 & 3.3 & 7.0 & 7.5 & 7.1 & 28.8 & 27 & -6.3 & 7.6 & 4.2 & -44.7 & 63.5 & 68.7 & 8.2 \\
\hline $\begin{array}{c}\text { Mean } \\
\pm \\
\text { SD }\end{array}$ & $\begin{array}{c}317.2 \pm \\
133.8\end{array}$ & $\begin{array}{c}316.6 \pm \\
127.4\end{array}$ & & $\begin{array}{c}14.37 \pm \\
1.464\end{array}$ & $\begin{array}{c}14.19 \\
\pm \\
1.201\end{array}$ & & $\begin{array}{c}9.555 \pm \\
0.891\end{array}$ & $\begin{array}{c}10.01 \pm \\
0.927\end{array}$ & & $\begin{array}{c}31.81 \\
\pm \\
14.55\end{array}$ & $\begin{array}{c}31.42 \\
\pm \\
13.93\end{array}$ & & $\begin{array}{c}9.365 \\
\pm \\
2.511\end{array}$ & $\begin{array}{c}9.000 \\
\pm \\
3.435\end{array}$ & & $\begin{array}{c}58.72 \\
\pm \\
15.54\end{array}$ & $\begin{array}{c}58.05 \\
\pm \\
15.17\end{array}$ & \\
\hline$P$ value & \multicolumn{3}{|c|}{0.8492} & \multicolumn{3}{|c|}{0.2005} & \multicolumn{3}{|c|}{0.0001} & \multicolumn{3}{|c|}{0.5742} & \multicolumn{3}{|c|}{0.4269} & \multicolumn{3}{|c|}{0.5431} \\
\hline
\end{tabular}

Table 4: The effect of He-Ne Laser light on human blood after 30 min irradiation (irradiance $9 \mathrm{~J} / \mathrm{cm}^{2}$ ) 
to haemolysis in hypotonic saline solutions. Results of osmotic fragility showed increasing the resistance of the membranes of erythrocytes to the hypotonic solution in both cases of irradiation than control but the increasing in resistance to hypotonic solution by non-coherent light is greater than that the effect of He-Ne laser (Figure 2). Statically by used one tailed paired $t$ test control versus non-coherent light is significant ( $\mathrm{P}$ value $=0.0015)$ and the median corpuscular fragility is equal to $3.51 \%$ of $\mathrm{NaCl}$ while control versus $\mathrm{He}-\mathrm{Ne}$ laser light is significant ( $\mathrm{P}$ value $=0.0274)$ and the median corpuscular fragility equal to $3.62 \%$ of $\mathrm{NaCl}$ solution (Figure 2). In other words irradiation of erythrocytes by non-coherent and coherent light decreases the osmotic fragility of erythrocytes (increased resistance to haemolysis by hypotonic solutions). In this study the effect of non-coherent light irradiation is more significant than that of He-Ne laser irradiation (Figures $3 \mathrm{~A}$ and 3B).

\section{Discussion}

The biological effects of low level laser light irradiation were first discovered and researched by Mester et al. in the 60-s, soon after the development of lasers [18]. The first low level laser therapy systems were based on $\mathrm{He}-\mathrm{Ne}(632.8 \mathrm{~nm})$ lasers. Currently diode lasers are replacing He-Ne lasers. Diode lasers are small, simple in maintenance, inexpensive in application and have a long lifespan. Red and infrared lasers are generally used for low level laser therapy (LLLT). There are reports about clinical trials of application of laser light of other colors, mainly blue and ultraviolet laser light, but at the moment such systems are not widely used. Light therapy with application of LED light instead of laser light (LED therapy) is another novel method of therapy. Sunlight was long known to improve acne, and this was thought to be due to antibacterial and other effects of the ultraviolet spectrum which cannot be used as a long-term treatment due to the likelihood of skin damage [19]. It was found that some of the visible violet light present in sunlight (in the range $405-420 \mathrm{~nm}$ ) activates a porphyrin (Coproporphyrin III) in Propionibacterium acnes which damages and ultimately kills the bacteria by releasing singlet oxygen. A total of $320 \mathrm{~J} / \mathrm{cm}^{2}$ of light within this range renders the bacteria non-viable [20]. Deep penetrating light therapy for 3 consecutive days has been shown to reduce the bacteria in the pores by $99.9 \%$. Since there are few porphyrins naturally found in the skin, the treatment is believed safe except in patients with porphyria [21]; although eye protection is used due to light-sensitive chemicals in the retina. The light is usually created by fluorescent lamps, or very bright LEDs. The influence of low level laser irradiation

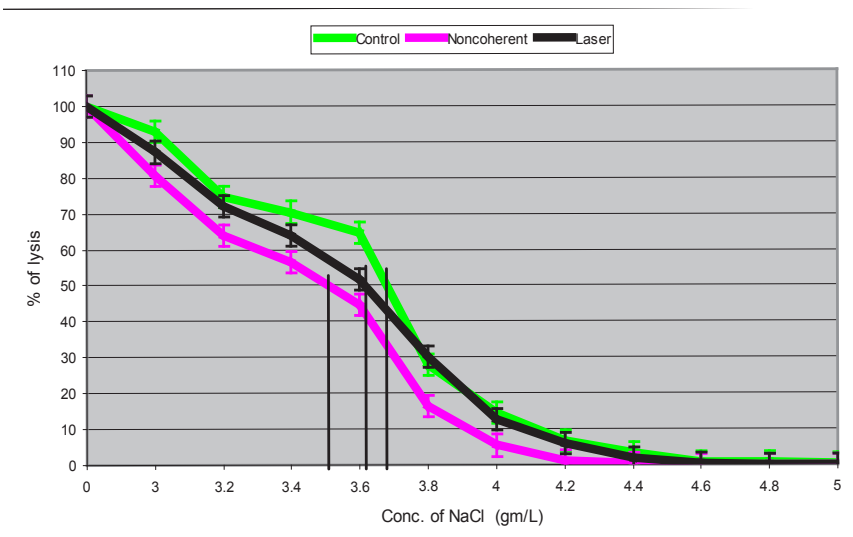

Figure 2: Mean and Standard deviation of osmotic fragility of Erythrocytes in case of control and irradiated erythrocytes with non-coherent and $\mathrm{He}-\mathrm{Ne}$ laser.

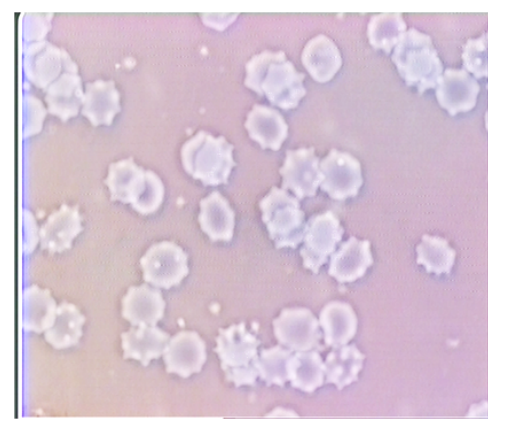

Figure 3A: Micrograph of a blood film from untreated control blood showed stored blood with change in the membranes of erythrocytes.

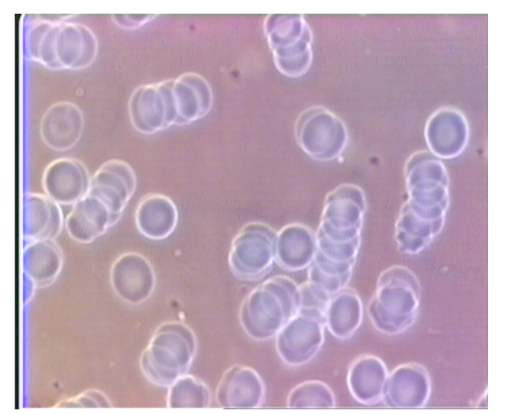

Figure 3B: Micrograph of a blood film from whole blood following irradiation showing improvement of cell membrane of erythrocytes (By using c.c.d. camera microscope).

on the organism has several clinical and biological effects, including anti-inflammatory, immunostimulatory, neurotrophic, analgesic, desensitizing, bactericidal, antiedemic, normalizing the blood rheology and hemodynamics effects (depending the condition of the patient and the pathology). Accordingly LLLT can be applied for the therapy of several pathologic conditions in various branches of medicine, including disorders. The current study was undertaken to assess the effects of non-coherent and He-Ne laser on human blood in vitro and how induced modifications on some rheological constants of the blood and also to assess the significance of these modifications. The results of this study have effectively demonstrated that the irradiation of blood at low doses and power densities leads to the following effects without causing any blood cell damage.

The biostimulating effect of light used opposes the physiologic destruction phenomenon ( $\mathrm{RBC}$ aging), leading to a rising viability of the cells in the circulatory system (i.e. raising resistance to the mechanical factors, such as spleen or micro vessels, where the spleen, as well as liver or micro vessels, acts as a blood filter, selectively destroying those blood cells whose membrane suffered alteration from their normal form. This effect is resembles the results of [22] which revealed that low powered $\mathrm{He}-\mathrm{Ne}$ laser irradiation produced a protective effect on RBC membranes, reducing hypotonic hemolysis and stabilizing the cell membrane.

RBC, HGB and HCT were strongly influenced by non-coherent and He-Ne laser action due to the strong absorption of irradiation light by HBG, but without damaging the RBCs. The mature red blood cell is a relatively simple structure whose entire function is geared towards packaging hemoglobin molecules efficiently, delivering them from the lungs to the microcirculation and back every 11 seconds, and keeping them in a functioning state for 120 days. Effective function of the red 
blood cell depends on: 1) its strongly negative surface charge (derived from surface glycoproteins) which permits it to repulse other circulating cells, thereby preventing "clumping;" 2) its unique doughnut-like shape, which is rheologically highly efficient and permits rapid flow of the cells through capillaries; and 3) its ability to prevent oxidative stress to the hemoglobin molecule, thereby maintaining the four iron atoms on each hemoglobin molecule in the ferrous $\left(\mathrm{Fe}^{2+}\right)$ state, in which configuration they are able to bind oxygen reversibly. Since the cell contains no nucleus and has no capacity to synthesize proteins, damaged molecules cannot be replaced during the red blood cells long lifespan. The shape of the cell is maintained, the cell's volume is regulated, and hemoglobin and other important molecules in the cell (such as membrane lipids and structural proteins) are protected from oxidation by enzyme systems that are driven by glucose catabolism, either via the Embden-Meyerhof pathway or the Hexose-monophosphate shunt.

The normal red blood cell is relatively impermeable biconcave disc which maintains osmotic equilibrium with the surrounding medium. As the surrounding medium becomes hypotonic, fluid will be taken into the cell to maintain stability. Eventually under very hypotonic conditions the cell will fill to capacity and rupture.

The irradiation of red blood cells by solar simulator for $12.2 \mathrm{~J} / \mathrm{cm}^{2}$ and irradiation of red blood cells by He-Ne laser for $9 \mathrm{~J} / \mathrm{cm} 3$ makes the red blood cells have increased capacity to expand and withstand more low hypotonic solutions that lyses un-irradiated normal blood cells. They thus exhibit decreased osmotic fragility (increased resistance of the cells to hypotonic solutions). These finding resembles that of [23] who found that decreased in osmotic fragility by used light irradiation at wave lengths $700-1200 \mathrm{~nm}$. Also this result resembles that of [22] who reported that low powered lasers stabilized stored erythrocytes in hypotonic solution and reduced the drop in deformability for stored erythrocytes [24]. But in this study the irradiation of red blood cells with non-coherent light decreased osmotic fragility (median osmotic fragility $=3.51 \mathrm{gm} / \mathrm{L}$ of $\mathrm{NaCl}, \mathrm{P}$ value 0.0015$)$ than that of irradiation by He-Ne laser (median osmotic fragility $=3.64 \mathrm{gm} / \mathrm{L}$ of $\mathrm{NaCl}, \mathrm{P}$ value 0.0274).

It is generally believed that erythrocytes, in circulation or in vitro, may undergo a variety of shape alterations, and these changes could be both reversible and irreversible. The discocyte-echinocyte transformation, for example, is a well known reversible shape change [25]. Solar spectrum from $250 \mathrm{~nm}$ to $700 \mathrm{~nm}$ is considered a primary source of light that elicits biological effects. Approximately $40 \%$ of the UV radiation of the sun falling on the skin is known to be transmitted through the stratum corneum to viable epidermis [26]. The equivalent of the entire blood volume of an adult may pass through the skin and potentially be irradiated in about $20 \mathrm{~min}$ under sunlight exposure [27]. Thus, we used human RBCs as a test model to assess coherent light and non-coherent light to improve the rheological properties of red blood cells. The capillary boundary between epidermis and dermis allows capillary vessels to lie close to the skin surface, permitting the blood and important components of immune system to be exposed to light [27].

\section{Conclusion}

The exposure of the blood to non-coherent light and $\mathrm{He}-\mathrm{Ne}$ laser improve its rheological properties and decreases the osmotic fragility of erythrocytes (increases the resistance of erythrocytes to hypotonic solution). The effects of light irradiation are better in case of non-coherent light due to various wave lengths in non-coherent and absorbed by the blood to give these effects. So the non-coherent light such as that emitted by solar simulator or Light emitting diodes (LEDs) becomes a promising alternative, because of its low cost and easy handling in these applications. It was observed that the therapy with non-coherent light has been more efficient than that with laser in the improvement of properties of human blood cells in vitro.

\section{Acknowledgment}

Thanks to the staff and members of the department of medical application of laser and the department of photochemistry and photobiology in NILES.BI thank them for the pleasant cooperation. I am grateful for their active support.

\section{References}

1. Lundeberg T, Malm M (1991) Low-power HeNe laser treatment of venous leg ulcers. Ann Plast Surg 27: 537-539.

2. Kipshidze N, Sahota H, Wolinsky H, Komorowsky RA, Boerboom LE, et al. (1994) Photoremodeling of Atherosclerotic wall inhibits myointimal hyperplasia following balloon angioplasty. Circulation 90: 327-332.

3. Moroff G, Lubanc NLC (1994) The influence of gamma irradiation on red cel and platelet properties. Transfus Sci 15: 141-148.

4. Anderson K (2003) Broadening the spectrum of patient groups at risk for transfusion-associated GVHD: implications for universal irradiation of cellular blood components. Transfusion 43: 1652-1654.

5. Wasik M, Gorska E, Modzelewska M, Nowicki K, Jakubczak B, et al. (2007) The influence of low-power helium-neon laser irradiation on function of selected peripheral blood cells. J Physiol Pharmacol 5: 729-737.

6. Halevy S, Lubart R, Reuveni H, Grossman N (1997) 780 nm Low Power Lase Therapy for Wound healing in Vivo and in vitro Studies. Laser Therapy 9: 159 164

7. Zalesskaya GA, Sambor EG (2005) Interaction of Low- Intensity Laser Radiation With Blood and Its Components. J Appl Spectrosc 72: 242-248.

8. Korolevich AN, Oleinik TV, Khairullina AY (1992) Optical Methods of Studying The Effect of Laser Radiation on Human Erythrocytes. J Appl Spectrosc 57: 651-654.

9. Sikurova L, Balis P, Zvarik M (2011) Penetration of laser light through red blood cell ghosts. J Photochem Photobiol B 103: 230-233.

10. Mi XQ, Chen JY, Zhou LW (2006) Effect of low power laser irradiation on disconnecting the membrane-attached hemoglobin from erythrocyte membrane. J Photochem Photobiol B 83: 146-150.

11. Cui Y, Guo Z, Zhao Y, Zheng Y, Qiao Y, et al. (2007) Reactive effect of low intensity $\mathrm{He}-\mathrm{Ne}$ laser upon damaged ultrastructure of human erythrocyte membrane in Fenton system by atomic force microscopy. Acta Biochim Biophys Sin (Shanghai) 39: 484-489.

12. Gulsoy M, Ozer GH, Bozkulak O, Tabakoglu HO, Aktas E, et al. (2006) The biological effects of $632.8-\mathrm{nm}$ low energy He-Ne laser on peripheral blood mononuclear cells in vitro. J Photochem Photobiol B 82: 199-202.

13. Brill AG, Shenkman B, Brill GE, Tamarin I, Dardik R, et al. (2000) Blood irradiation by $\mathrm{He}-\mathrm{Ne}$ laser induces a decrease in platelet responses to physiological agonists and an increase in platelet cyclic GMP. Platelets 11: 87-93.

14. Zalesskaya GA, Sambor EG, Kuchinskii AV (2006) Effect of Intravenous Lase Irradiation on The Molecular Structure of Blood and Blood Components. J App Spectrosc 73: 115-122

15. Mi XQ, Chen JY, Cen Y, Liang ZJ, Zhou LW (2004) A comparative study of 632.8 and $532 \mathrm{~nm}$ laser irradiation on some rheological factors in human blood in vitro. J Photochem Photobiol B 74: 7-12.

16. Siposan DG, Lukacs A (2000) Effect of Low-Level Laser Radiation on Some Rheological Factors in Human Blood: an in vitro Study. J Clin Laser Med Surg 18: $185-195$

17. Dacie JV, Lewis SM (1975) Practical Hematology. (4thedn), J and A Churchill, London.

18. Mester E, Szende B, Spiry T, Tota JG (1972) Die Wirkung wiederholt angewandter Elektrokoagulation und Laser-bestrahlung auf die Haut von Mäusen. Z Exper Chirugie 5: 115-126.

19. Health effects of UV radiation (2010) Ultraviolet radiation and the INTERSUN Programme. World Health Organization. 
Citation: Mostafa YM, Amin SN, Abdalwahab S, Elsherbini AAM (2013) Effects of Non-Coherent and Coherent Light on Complete Blood Picture and Osmotic Fragility of Human Blood. J Blood Disorders Transf 4:134. doi:10.4172/2155-9864.1000134

20. Papageorgiou $P$, Katsambas A, Chu A (2000) Phototherapy with blue (415 nm) and red $(660 \mathrm{~nm})$ light in the treatment of acne vulgaris. Br J Dermatol 142: 973-978

21. Hebel JL, Poh-Fitzpatrick MB (2009) Congenital Erythropoietic Porphyria. eMedicine.

22. lijima K, Shimoyama N, Shimoyama M, Mizuguchi T (1991) Red and green lowpowered He-Ne lasers protect human erythrocytes from hypotonic hemolysis. J Clin Laser Med Surg 9: 385-389.

23. Chludzinska L, Ananicz E, Jaroslawska A, Komorowska M (2005) Near-infrared radiation protects the red cell membrane against oxidation. Blood Cells Mol Dis 35: 74-79.
24. lijima K, Shimoyama N, Shimoyama M, Mizuguchi T (1993) Effect of low power $\mathrm{He}-\mathrm{Ne}$ laser on deformability of stored human erythrocytes. J Clin Laser Med Surg 11: 185-189.

25. La Celle PL, Kirkpatrick FH, Udkow MP, Arkin B (1972) Membrane fragmentation and $\mathrm{Ca}++-$ membrane interaction: potential mechanisms of shape change in the senescent red cell. Nouv Rev Fr Hematol 12: 789-798.

26. Everett MA, Yeargers E, Sayre RM, Olson RL (1966) Penetration of epidermis by ultraviolet rays. Photochem Photobiol 5: 533-542.

27. Kornhauser A, Wamer WG, Lamert LA (1996) Cellular and molecular events following ultraviolet of skin. (5thedn), Taylor and Francis.
Citation: Mostafa YM, Amin SN, Abdalwahab S, Elsherbini AAM (2013) Effects of Non-Coherent and Coherent Light on Complete Blood Picture and Osmotic Fragility of Human Blood. J Blood Disorders Transf 4:134. doi:10.4172/21559864.1000135 